\title{
Impact of Change in Structure of Government on Health Service Delivery: A Case Study of Dang District of Nepal
}

\author{
Amrit Khanal ${ }^{1 *}$, Bishal Bhandari' ${ }^{1}$ Pradish Poudel1 ${ }^{1}$, Pravakar Dahal ${ }^{1}$
}

${ }^{1}$ School of Medicine, Chitwan Medical College, Tribhuvan University, Chitwan, Nepal

\section{ARTICLE INFO}

Article history:

Received: 17 March 2021

Revised: 27 April 2021

Accepted: 11 June 2021

*Correspondence:

Amrit Khanal

School of Medicine,

Chitwan Medical College

E-mail:

khanalamrit3@gmail.com

Citation:

Khanal A, Bhandari B,

Poudel P, Dahal P. Impact of

Change in Structure of

Government on Health

Service Delivery: A Case

Study of Dang District of

Nepal. MedS. J. Med. Sci.

2021; 1(1): 112-127

\begin{abstract}
ABSTARCT
INTRODUCTION: Nepal has changed its structure of governance from a centralized into decentralized system to improve its health service delivery to people. This paper aims to highlight the impact of this changed structure in health service delivery during this transition phase. Thus a cross sectional study was performed to study the impact, where semi-structured interviews in Nepali with officials of different health institutions under different tiers of government was conducted. MATERIALS AND METHODS: An inputprocess-output framework was applied to study the components of health service delivery. The data obtained was transcribed into English language and content analysis was executed under several headings. RESULTS: After analyzing the findings, mixed impact was observed with various challenges and opportunities in the way ahead for improving the health service delivery. A positive impact on the physical infrastructure was seen along with opportunities as well as challenges in human resource procurement. Management of budget as well as logistics have become difficult. Plan as suitable as possible are being made meanwhile, organizing the health system is becoming haphazard. Staff management along with training them and coordination among agencies have become more tedious. However a good outcome was present in aspects of service utilization and community participation. CONCLUSIONS: Nepal as a developing country has been making an effort in the way forward on improving its health service delivery and further research on this field is necessary. Also robust framework and policies to drive the country in delivering an improved health service is required.
\end{abstract}

KEY WORDS: Decentralization, health, impact, public health

\section{INTRODUCTION}

The Government of Nepal, through its health ministry, plays a vital role in delivering health services by strengthening health systems and by the generation of human, financial and other resources. This permits health organizations to accomplish their goals of improving health, reducing health inequalities, securing equity in health care financing, and acknowledging the population needs. Nepal is now decentralized into seven provinces and is further sub-divided into 293 urban municipalities and 460 rural municipalities. The newly formed municipalities are as a whole larger, endowed with greater authority, and hold the responsibility to fulfil the promises, made to the people of Nepal. The local

level elections were undertaken in three phases from May to September 2017, and provincial elections were held in November and December 2017. The constitution lays out a vision for a federal state comprised of three tiers of government: federal, provincial and local.

Dang district lies in mid-western part of the country. This district consists of larger easterly and upstream portions of the parallel inner Terai Valleys of Dang and Deukhuri, along with enclosing ranges of hills and mountains. There are two sub-metropolitan cities (Ghorahi and Tulsipur), 1 municipality (Lamai) and 7 rural municipalities (Bangalachuli, Babai, Rapti, Rajpur, Gadhawa, Dangisaran, Shantinagar) and 3 election areas in Dang district.

A thorough review of literature, regarding the impact of change in structure of government in 
health service delivery was done. Only a few papers were present to give a detailed overview of the impact. Thus, a study was required to explore the impacts created in the health service delivery, which created an enthusiasm among the authors to dig through the opportunities and challenges that the federal system has presented in Nepal. This contribution could allow the policy makers to point out the actual scenario and deal with such scenario in upcoming days. This paper aims to highlight the current scenario of health service delivery that is existent in the present reformed structure. The impacts discovered could be very useful in guiding the authorities of all three tiers of government systems to make effective health service delivery at the grass-root level. This paper also highlights the key aspects to be concerned in delivering a public-oriented health service.

\section{Present Structure of Health Service Delivery}

Nepal has adopted a new decentralized municipal based health service delivery system, to improve efficiency, accessibility, effectiveness, quality and equity. Nepal's health infrastructure and development standards 2074, classifies health services delivering institutions into five levels: Community level (Health post or Community health units); Primary hospitals; Secondary hospitals; Tertiary hospitals; Academic or Super specialty hospitals (Table 1 ).

Table 1। Present Structure of Health Service Delivery

\begin{tabular}{|c|c|c|}
\hline S.N & Level of government & Type of health service delivery institution \\
\hline \multirow[t]{2}{*}{1} & Local level & \\
\hline & Ward level at village or urban municipality & Community Health Unit or Health Post \\
\hline \multirow[t]{2}{*}{2} & Local level & \\
\hline & Ward of sub/metropolitan city & Urban Health Promotion Center \\
\hline \multirow[t]{2}{*}{3} & Local level & \\
\hline & Rural municipality & Primary Hospital Class B \\
\hline \multirow[t]{2}{*}{4} & Local level & \\
\hline & $\begin{array}{l}\text { Municipality or Sub Metropolitan } \\
\text { or metropolitan }\end{array}$ & Primary Hospital Class A \\
\hline \multirow[t]{2}{*}{5} & Province level & Secondary Hospital \\
\hline & & Provincial Health Science Academy \\
\hline \multirow[t]{3}{*}{6} & Federal level & Tertiary hospital \\
\hline & & Super Specialty Hospital \\
\hline & & Federal Health Science Academy \\
\hline
\end{tabular}

The catchment population and geography forms the basis for assigning number of beds and identifying the required number of health workers. The National Health Policy 2014 ensures fundamental right to health through Universal Health Coverage (UHC) by making sure that access to quality basic health services are free of cost [23]. The nation's commitment towards achieving UHC, stands on four strategic principles: Equitable access to health services, quality health services, health system reform and multi-sectoral approach [20].
Series of changes that occurred after the introduction of federal system have created a great impact on the structural organization of government and has led to the repositioning role of governments in health as well as other social sectors. Structural change has a troublesome impact on managerial, behavioural and organizational outcomes. It indicates that many problems regarding the various aspects of the health service delivery are going to have positive as well as negative impacts [2]. Organizational change is more often structural in orientation, 
where the administrative positioning is altered, for example, for strategy setting, financing, operations or accountability [3].

Structural changes generally imposed on public health care services comprises the creation of new organizations, agencies and positions, and the merging or abolition of old ones. Also, the operational units specifically are at greater risk of being reconfigured, merged or broken up or retasked to alternate sets of roles, duties and responsibilities. Likewise, reporting and accountability arrangements have a probability to be reformed, along with new financial mechanisms and even legal frameworks have to be reformed [3]. This has indicated that the change in government structure influences the different aspects of health service delivery as well. A good system of regulation is elementary to successful public health outcomes. Wide gaps prevail in the enforcement, monitoring and evaluation, resulting in a weak public health system [16]. So, we being a medical practitioner were very much keen to investigate the impacts of this reconfigured system on health service delivery.

\section{Literature Review}

A study to explore factors that influence healthcare quality in the Iranian context. The method applied was exploratory in-depth individual and focus group interviews with 222 healthcare stakeholders incorporating healthcare providers, managers, policy-makers and payers to explore factors impacting the quality of healthcare services available in Iranian healthcare organizations. It was discovered that factors of the service provider and the patient, factors relating to the healthcare organization, health service delivery system and the broader environment influences healthcare service quality [24].

Empirical literatures on the impact of decentralization, gave a summary and provided conclusions on its impacts on service delivery. Shah et al. summarized the findings as positive, negative and inconclusive where they have briefly described that, decentralization impacts the service delivery positively as well as negatively. They have also highlighted inconclusive findings of decentralization on service delivery [35].

A study that reviewed studies published from 2000 to 2016 with ample research designs to explore evidence on whether and how decentralization impacted health systems, conducted a systematic review of peer-reviewed journal articles from the public health and social science literature and included original research articles of low- and middle-income countries with quantifiable outcome measures and study designs that apply comparisons or statistical adjustments. They discovered mixed results regarding the effects of decentralization on health system indicators with positive impact on health system performance and health outcomes [6].

A structured review of published and grey literature till May 2015, adapting standard procedures to enlighten with an updated and comprehensive examination of the effects of decentralization in Low and Middle Income Countries (LMICs), incorporated 54 qualitative, quantitative and mixed methods studies conducted in 26 countries. They explored positive and negative impacts of decentralization of health systems in LMICs. Meanwhile, change in the structure of health service delivery has been shown to have positive effects on the system [25].

A study in Nepal to examine and understand the impact of decentralization at the district health service from service users and providers' point of view, which used non-probability purposive sampling, and performed in-depth interviews and focus group discussions in four primary health care institutions with service users, providers and other stakeholders. QSRNVivo7 Software was employed to investigate and classify the data under emerging themes. They discovered that decentralization was positively related with increased service access and utilization and improved service delivery [31].

All the above literature reviews presented us with varying impacts of change in structure of government in service delivery. This created a dilemma within us whether the decision to change the structure of government would positively or negatively impact the service delivery. Furthermore, taking the context of our country only a few studies and papers have been published to analyze the impact. So, this sparked a curiosity to explore the impacts of change in structure of government for health service delivery.

\section{Theoretical Framework/Conceptual framework}

In this paper, we have adopted the framework which was utilized previously by Panda and 
Thakur [29] where a input-process-output framework was applied and health service delivery was considered as the 'existential' function of the health system, and inputs, processes and outputs as 'operating domains' which in our study dynamically interact with each other. In the conceptual framework we proposed three levels of functions relating to inputs, processes and outputs. Each function encompassed key elements derived from the synthesis of information gathered through literature review and semi-structured interview.

Change in the structure of government has made the provision of social services such as education, health, water and sanitation leading to improved service delivery [7]. The quality and equity of access have not improved with the change in structure of health and education services [33]. This varying impacts caught our attention and drove us to investigate deeply into the context of our country, where the opportunities and challenges of implementation of federalism in the health system exist [36]. Still, they have not shed light on its impact on health services to the general public. The opportunities and challenges mentioned are specific to the internal environment comprising of input aspects (human resource, budgeting, essential medicine and supplies) and to some extent of the processing part (procurement of supplies, planning, policies and capacity building of health workers). The research has not addressed aspects such as physical infrastructure, coordination, monitoring and evaluation. Likewise, it has not commented on the external environment (political situation and community participation). Regarding all these aspects created a special interest for us in this particular field of study. Also, the wider implications of decentralization are poorly researched and inadequately understood in the context of Nepal.

\section{MATERIALS AND METHODS}

Nepal is transitioning from centralized to decentralized system of governance thus requiring reforms in several areas of the health service delivery. There are only a few studies that have been conducted to provide the detailed picture in the context of Nepal. This created an enthusiasm between the authors to contribute to the impact of change in the structure of government for health service delivery. This study is part of the author's community field posting in Dang district. The author's were posted at Provincial Hospital, District Hospital and Health Office, Dang, and were also posted at local level in Rapti Rural Municipality and its related health institution for two months duration with two weeks in each Provincial Hospital and Health Office and two weeks each in Lamahi Hospital and Rapti rural Municipality. The study was conducted from 19th poush 2075 to 3rd Falgun 2075. Official letters from the college were submitted to the respective institutions on the first day of each placement. Permissions were granted from the college as well as the respective government authorities. During the field study, author's conducted this study, thus the study site was Dang district with its provincial, district hospital and local rural municipality health system. A qualitative interpretive study of the management of the health service delivery was done. Interviews and interaction with 2 Medical Superintendent, 2 Sr. Public Health Officers, Head of Rapti Rural Municipality, 1 Senior A.H.W., 2 H.A. was done and were selected purposively. Interviews were conducted based on semi-structured interview guidelines. The guidelines were prepared with the consultation of the supervisor and were separate for different members. All the personnel were asked about the impact of change in structure of government and its impact in health service delivery. Before approaching any personnel for the interview or discussion, objectives of the study were explained and verbal consent was taken. The author's collected primary data in the form of verbatim and quotes. The interview time varied ranging from 1 hour minimum to 3 hours maximum and some of the personnel were even reinterviewed within 15 days due to their time restrains. The collected data was transcribed into English and coding, categorizing and content analysis was done regarding the several aspects of health service delivery. The data obtained from different individuals were extensively analyzed from each of the participants involved in the study and was found to be consistent with each other. This study was conducted in the initial stage of transition where all the system of governance were going through similar phase in bigger or smaller picture. So, the study can be a reference to all the institutions for addressing the possible impact and overcome the challenges. Thus, the trustworthiness of the study was addressed. The 
findings were discussed with theory and previous literatures.

\section{RESULTS AND DISCUSSION}

The main aim of this study was to highlight the impacts that has been created in different aspects of health service delivery after the change in structure of government. It includes components such as physical infrastructure, human resource, budget and budgeting and logistics. Likewise it also includes planning, organizing, staffing, directing, training, coordination, monitoring and evaluation, service utilization, coverage of health services, political situation and community participation. The impacts that have been created are variable in respect to each aspects. A thorough discussion might ease the authorities in the policy making to address the impacts and act accordingly in making the country progressive towards delivery of optimum health services. Thus, the positive and negative impacts of individual aspect are discussed herewith.

\section{Physical infrastructure}

Significant investment in health infrastructure is needed to adequately respond to the current and future health care needs. Change in the structure of government leads to increased spending on public infrastructure [8]. On interviewing the Medical Superintendent of Rapti provincial Hospital about the impact he felt after the change in the structure, he replied:

After the implementation of federalism, an effort was made to convert the zonal hospital into a provincial hospital with upgrading its bed capacity, laboratory and other different services and making it a medical center to serve remote districts with its upgraded services.

From the above statement, we can see the positive impact of change in the structure of government where an effort was made to upgrade the existing health services for effective health service delivery. The role of Provincial government is to prepare and implement plans of development and upgrading of infrastructure [20]. Adding to it, the head of Lalmatiya health post said:
The new infrastructure that we are seeing next to this old building was made possible after the change in the structure of government with better health policies. Also, the services will now be upgraded and added after the completion of new infrastructure.

This statement also clarifies the impact that we have seen after the reformation of government. Both the statement gives us a picture that the physical infrastructures which are an important aspect in effective health service delivery are being made in all the health institutions in all three levels of government. It is the responsibility of local government to recognize and organize resources required for health infrastructure development. Quality services delivery should be maintained and monitored on a regular basis after the upgrade [20].

Rapti Rural Municipality had made an attempt to expand its health services to rural areas within its jurisdiction in accordance to the new health policy provided by the ministry of health and population. So in the process of interviewing with the head of Health and Social Development Section. He commented that:

We have established three community health units in order to bridge the gap in service delivery in the rural aspects within this rural municipality with the aim to provide basic health services.

From the above statement, we can see the effort of the government in policy-making as well as effective implementation to fulfil the needs of the public which is quite a promising impact that was observed. Preparing procurement plan for infrastructure development, purchasing health equipment and instruments, managing contracts, supervising sites and managing financial accounting of infrastructure projects are the roles which were being done by Rapti Rural Municipality. Thus, the government is on the path of its infrastructure development standards and has been conducting well, which is a positive impact of change in structure. 


\section{Human Resources}

Head of Health office of Dang on talking with us presented a picture on human resources by saying:

After the implementation of the federal system, Provincial Health Directorate has come into action replacing the previous Regional Health Directorate which lacked adequate manpower and there was confusion in the role of Health Offices in the districts with no specific division of work. We have been acting as a bridge to fulfil the gap seen in communication between local government and Provincial Health Directorate. Also, after the operation of local governments all the health posts, primary health centers and district hospitals came under the jurisdiction of respected local government which has been transferring the health workers from the respective health institutions without adequate administrative knowledge into Health and Social Development Section. Also, it was difficult for us to train all the Health workers or to transfer our staff to the local government. This transition period has become hard for us.

Here the drawbacks of change in the structure are discussed and dilemmas in the functions are prevalent. Without proper planning on creating the new organization and dismissing the old ones have created confusion in their functions. Also, without adequate and trained manpower at provincial and local government level, health service delivery has been facing negative impact and has become troublesome for the public to reach out for health services. The health offices must be empowered to bridge the gap in communication, and knowledge on managerial aspects must be delivered to the officials who are transferred.

Human resources are the most crucial component of the health service delivery system, in converting available pharmaceuticals, medical technology and preventive health information into better health for a nation. The ramifications of decentralization for human resources for health are greatly affected by the level to which political and/or administrative power is transferred, the way the new roles are defined, what skills are present at the local level, and what administrative links exist between the different management levels and between the central health authorities [15]. These problems were associated with collapse and formation of new government bodies which is exactly seen in our context also [3]. The health personnel appointed at local level (eg, paramedics at service outlets) are primarily trained to offer health services and therefore, lack skills on management and procurement at large [35] which has also been presented by the Head of Health office of Dang.

A significant impact was observed after the local government came into effect. On interviewing about the status of human resources the Head of Health and Social Development Section of Rapti Rural Municipality communicated with us by saying:

After the stabilization of local government, we have appointed a Medical Officer on a rotational basis temporarily to two health posts to ensure good service delivery to the public. In addition to it, two lab assistants were also appointed temporarily to start basic laboratory investigation services which was a great achievement for us. Likewise, the establishment of community health units needed human resources to operate so, we have appointed a team of Auxiliary Health Worker, Auxiliary nursing Midwife and Office Assistant as per the National Health Policy.

The above statement clarifies that after the local government came into effect, they have made an effort to provide quality health services by making sure that the services were being delivered by competent health personnel. To cope with the deficient in human resources, increment in the desired human resource can be done through recruiting on a temporary basis [35], which was the exact scenario presented to us by the respected personnel of Rapti Rural Municipality. They were utilizing the opportunity of change in structure to cope with the deficient manpower and increase the quality of health service delivery. Optimum service utilization must also be ensured to improve health service delivery. However, the interference of local authorities in recruitment processes was present where there would be a chance to recruit the person 
of interest of the local authorities and thus the process needs to be transparent as well [25].

The transfer of human resources to local control is a more complicated procedure than the hand-over of facilities or equipment. The difficulties mentioned are formation of new organizational structures and positions at different levels, amendment of job explanation, deciding the way to reallocate present staff to newly formed organizational structures, moderating if the staff refuse the transfer and dealing with them [15]. Similar opinion was addressed by the Head of Health office as:

The most difficult challenge government has been facing, is the reallocation of staff to provincial and local level. This has been more complicated than other departments with formation and dissolution of most of the organizations and the resistance of the staffs to be reallocated to their mentioned organization.

The difficulty in reallocating staffs according to the change in structure as mentioned in the above statement impacts the efficiency of health service delivery, as the chain of health service delivery seems to be interrupted. Major difficulty in human resource management where civil servants are resistant to change in the structure which was in line with our findings [19]. The scheme that government has brought up to encourage the transfer of staffs to the local level by promoting them should be made attractive by adding more schemes. Not limiting to it the provincial service commission formation and execution must also take effect in a rapid pace to solve the issue.

\section{Budget and Budgeting}

Fiscal decentralization involves transferring authorities for expenditures and/or revenues to lower levels of government which has an impact on health sector funding as well. It creates budgeting issues in particular scenarios such as in decentralized contexts, in highly donor-dependent countries, and in fragile states as the fund channels to the health system [40]. Almost 50\% of Nepal's health budget is made up of international aid [37]. Thus, Nepal is bound to have some issues regarding the budget. On discussing with the Head of Health office he commented:
Previously different Non-Governmental Organizations whether it be National or International would coordinate with us to channel their funds directly into health posts and primary health centers. But after the change in structure, additional coordination with the provincial government and local government had made the process lengthy in channeling the funds so without appropriate financial backup, the health service delivery by the grass-root level institutions have become troublesome.

The statement above gives us a picture that the health service delivery of Nepal as a whole is dependent on assistance from different national and international non-government organizations. Considering this fact and addressing our change in structure, inadequate preparation of facilitating the organizations may have a negative impact in all the programs and operations being carried out. Regarding the budget related aspects he said, that release of program budgets from the center was often late which shows that the current practice of decentralization seems to be very difficult which is in line with our result [26]. Thus, it is necessary to facilitate the ease in flow of funds through appropriate framework of rules and regulations to immediately address this issue and to prevent any impact on health service delivery.

On asking about the budget allocation by the local government to health sector the Head of Health and Social Development Section of Rapti Rural Municipality communicated with us by saying:

The local representatives are more focused on developing the infrastructure like roads, drinking water etc. and to show development they have made, they have allocated much of their budget in it. This allows a limited budget to be allocated for the Health and Social Development Section. This is making us carry out our programs in a limited amount of budget.

The statement above presents us with the problem of health and social development section being overshadowed a bit more than the previous system where an organization was especially dedicated to improving the health organizations. Health sector 
priorities (often set at national level) may be deranged with sub-national level budgets and spending targets (e.g. health can be de-prioritized in sub-national budgets) [40]. The local representatives thus are needed to be trained and made aware of the importance of strengthening the health sector and the catastrophic situation that is eminent if it is neglected.

Moreover, he also added:

The local government has allocated its budget according to the local health needs of the public. Since sickle cell anemia was more prevalent in our Rural Municipality we have allocated budget to help the marginalized people who were not getting it previously. Also, the budget to start laboratories, appointment of medical officers and other health workers were also made, addressing the need as there was no health service delivery by private health organizations.

This depicts that despite the low budget allocation to the health and social development section they are utilizing the budget productively to ensure effective health service delivery. Due to the closeness of the local government to the people, the federal context provides fertile ground for more efficient budgeting and requirement-based and evidence-based planning [35]. The opportunity here is that the government can train the respective stakeholders in budgeting and planning aspects to function effectively in addressing the needs and making health service delivery more publicly oriented and also it is to be ensured that the people who are affected would get the funds.

\section{Logistics}

Enhancing the quality of care relies on the efficient logistics activities within hospitals [10]. This clarifies the importance of logistics in health service delivery as well. So, we asked Head of Health office of Dang and he commented by saying:

After the change in structure, provincial stores send the essential materials which were funded by International NonGovernmental Organizations such as vaccines, family planning materials, free of cost drugs, Ready to use Therapeutic Food
(RUTF) in nutritional care and other programs related logistics. But due to the gap in manpower we were working as a bridge to facilitate the process. The change in structure has caused poor procurement planning and budgeting in provincial level, quantification and forecasting in local level and delay in procurement steps in both levels has created the scarcity of essential supplies which has been creating problems in delivery of services.

The transmission of authority to the subnational level during this transition phase has created a difficult situation to make health logistics available in time which seems to have a negative impact in health service delivery at grass-root level. Due to the delay in supply of the adequate logistics, effectiveness of health service delivery degrades thus, creating a delay in promptly addressing the health needs and smooth operations of different programs. Poor procurement planning and budgeting, poor quantification and forecasting, delay in procurement process and order processing are some of the causes of inadequacy of logistics in the health systems which is in line with our result [17]. Hence, immediate fulfillment of vacant positions of newly formed organizations is crucial and capacity building on planning, budgeting, quantification and forecasting is essential and efforts must be made from all levels to alleviate delay in procuring logistics.

The constitution designates the management of Basic Health Care Services (BHCS) to the local level. This comprises the procurement of essential medicines and medical supplies to ensure the efficient delivery of the BHCS [35]. The Head of Health and Social Development Section of Rapti Rural Municipality told us that:

Since the shift of authority to subnational levels, we were able to procure additional free of cost drugs other than that provided by the government along with essential laboratory and surgical equipments.

It seems that changes in structure have given an advantage to the local government in delivering efficient health services by procuring the logistics as per need. This is an opportunity for the local government to do some research with more 
prevalent diseases and procure the drugs to meet the needs. Also, appropriate guidelines should be made to direct the local government.

\section{Planning}

A setting of change in structure may help in achieving more effective planning and decisionmaking in the health sector, but it can also face new challenges, especially in finding the right equilibrium between national and local-level planning [40]. Head of Health and Social Development Section of Rapti Rural Municipality on talking with us said:

Now after the introduction of new structure we can plan our health service delivery according to the needs prevalent in our jurisdiction.

Thus, it is clear that the needs prevalent at local level can be addressed through local level planning. The federal context provides fertile ground for more effective, needs-based and evidence-based planning [35] and also adding to it, they mentioned that the local and provincial government, if enabled can prioritize and plan for the health sector from different resources. Furthermore, adding to it he commented that:

Local representatives practice, public participation in planning and we receive the most important problems prevalent in the society, prioritize them and address the most important problems through appropriate planning. This process has made the plan more successful.

The statement above mentions the effort of the local government to make plan as inclusive as possible and address the top priority problem, and make the health service delivery more efficient. If participation is based on representation, as is seen in most of the cases, it is important for the representatives to keep in touch with the people they stand for, so that the interests of the people represented are conveyed which is the scenario in our context as well [14]. Also, operational planning should include a wide range of people instead of being dictated by the manager/boss. At least, all those who are meant to implement the plan should be involved in the process to make the planning successful [40]. This highlights the importance of public participation in planning and inclusive planning must be encouraged by both provincial and federal government levels to local levels for efficient service delivery. Hence, local government should enforce a protocol for planning so that the issues necessitating immediate address are not overshadowed.

\section{Organizing}

The shift in balance of power necessitates the formation and dissolution of new organizational forms, the transfer of health-care managers and a corresponding shift in their roles and responsibilities. Although it is possible to suggest that this process of organizing and reorganizing has an impact on service delivery, decentralization and centralization influences the ways in which organizations are handled and the way they relate to other local and national organizations [29]. On interviewing the Head of Health Office, Dang similar responses were obtained where he said:

There has been some organizing and reorganizing after the change in structure. At first the District Public Health Office (DPHO) was decided to be dissolved but again due to its significant impact on health service delivery it was said to be retained and be functioning as Health Office. This dilemma had interrupted the service delivery to local governments. Also, the dissolution of Regional Health Directorate and formation of Provincial Health Directorate and the introduction of the Provincial Ministry of Social Development were meant to ease the service delivery but being in the transitional phase the health service delivery was seen to be affected.

This statement clarifies the organizing and reorganizing going on during this transition phase and the created dilemma. Moreover, the impact caused by the organizing and reorganizing has seen to be affecting the service delivery. It is therefore essential to make a robust framework keeping in mind the impact of dissolution and formation of new organizations and the roles and responsibilities of organizations should be mentioned beforehand with adequate human resources so that the impact 
on health service delivery is not so severe during the transition phase.

\section{Directing Health Service Delivery}

On interviewing the Head of Health Office about the reformations in direction after the change in structure he commented by saying that:

The zonal hospitals which have now converted into provincial hospitals were directed by the provincial government, the district hospitals came under the jurisdiction of the local government unless it lied in the provincial capital. Moreover, all the primary health care centers, health posts, urban health clinics or community health units were directed by the respective local governments. This has been thought to improve the efficiency of the health institutions in health service delivery.

The above statement clarifies the directing bodies of different health institutions at different levels. Furthermore this change is expected to heighten the efficiency of health service delivery by these institutions. Decentralization involves different mechanisms to shift fiscal, administrative, ownership, and/ or political authority for health service delivery from the central Ministry of Health $(\mathrm{MOH})$ to alternate institutions which are thought to promote health sector performance [39]. Thus, to achieve improved efficiency of health service delivery after the change in structure, health institutions require time to time direction for activities according to the situation which the local government should be capable of providing.

\section{Coordination}

Coordination whether it be within the different government institutions or with the several NonGovernmental Organizations (NGOs) is crucial in effective health service delivery especially in the recent decentralized context of Nepal. The health system that sets a target to be efficient, equitable and effective necessitates a considerable degree of territorial coordination in terms of its strategic guidance, financing and services delivery functions [34]. On talking with the Head of Health Office at Dang about the coordination between agencies he commented by saying:
After the change in structure, coordination has become very important because several new organizations are being formed at subnational levels whether it be provincial ministries, provincial health directorate, provincial health stores or local governments. This requires a proper communication among themselves otherwise a gap would be present in health service delivery which was exactly the situation at present. The functions which we were carrying out were decided to be shifted into the provincial organizations but due to the lack of human resources and expertise we were bridging the gap until appropriate measures were taken. Furthermore, the aids which were made available by different national and international Non-Governmental Organizations were also being mismanaged due to the same reasons of inadequate human resources and expertise in the new organizations. Thus, we were experiencing hindrance in the effective health service delivery.

The above statement presents us with the importance of coordination among several governmental and nongovernmental organizations in delivering an efficient health service delivery. New organizations in sub-national level are coming up slowly in their full-fledged form but till then problems due to inadequate human resources and expertise are creating a gap in coordination among these agencies and previously existing agencies are providing them help which seems to be supporting the problems due to change in structure. Collective ability to communicate in a productive way decides whether the results are good for people and health systems. Furthermore, lack of coordination diffuses effort, can sometimes disable or deteriorate systems entirely [40]. The integration of top-down, vertical donor programs into decentralized systems is another major issue, particularly where a huge proportion of public service funding is external [27]. The government needs to address this situation of lack of coordination among the governmental organizations as well as the National and International organizations which are playing a crucial role in our health service delivery. The Government of Nepal should clear all the obstacles 
hindering effective communication and coordination, and should form a mechanism which contributed especially for coordination and ease it among different intergovernmental organizations and non-governmental organizations to provide a favorable working environment leading to improvement of our health service delivery.

\section{Training}

Decentralization has brought a new requirement for management skills and complex administrative relationships [32]. Thus, to address the gap, training to health professionals is required. On interviewing the Head of Health and Social Development Section of Rapti Rural Municipality, he said:

We were providing preventive and curative health services in our respective institutions but the recent change in structure has transferred us to the Rapti Rural Municipality. But we are not trained enough to perform all the administrative aspects.

The statement here depicts the inadequate expertise of health professionals to deal with the administrative aspects. This may create a problem in efficient health service delivery. The deputed health personnel at local level (e.g., paramedics at service outlets) were mainly trained to provide health services and thus, lack expertise on management and procurement at large [36]. The government thus needs to organize training on different managerial aspects to these officials, which helps in their capacity building thus improving efficiency of health service delivery.

The Health Assistant (H.A.) at one of the Health Posts of Rapti Rural Municipality on talking with us said:

Before the change in structure, we used to get different refresher trainings on the programs that were running at present and also used to get trained about the recent updates in health service delivery but after the change in structure, we were not getting any training program even in a year which is depriving us with the opportunity to be updated with the recent trends in health service delivery.
The H.A. had presented us with the problem of not getting any regular training in different programs as well as health service delivery leading to inability to address the changing needs of health service delivery which keeps on changing every now and then. In support to our findings, deprivation of technical knowledge and skills and the unavailability of a supportive network or adequate educational opportunities hinder personnel from making enhancements [13]. Furthermore, the lack of in-service training and of training curricula that reflects field realities discourages health workers from following effective strategies. These training must be organized uninterrupted by facilitating organizations providing training to health workers and the Health Office must be utilized in a proper way to continue the training occurring yearly to keep up with the recent trends of health care service delivery.

\section{Monitoring and Evaluation}

Monitoring is defined as collecting all data together to examine the progress of implementation of activities. Evaluation is based upon monitoring and assessing whether the desired outputs of a National Health Policies, Strategies and Plan (NHPSP) intervention have been achieved. So, on the basis of the evidence gathered through Monitoring and Evaluation (M\&E) processes, reviews are done to assess overall progress and performance and to point out the problems and take corrective actions [40]. Thus, we interviewed Health Assistant of one of the Health Posts of Rapti Rural Municipality and he said that:

After the change in structure all the reporting was done to the Rural Municipality and they were the authority responsible for monitoring and evaluation of our health.

Reporting system must be strengthened by capacity building of the respective authorities. Adding to it, Head of Health and Social Development Section of Rapti Rural Municipality also said that: 
After the change in structure power was shifted to subnational levels and hence we were monitoring and evaluating the performance of our health institutions. It has become easy for us to point out our problems while implementing different plans, policies and strategies which has made monitoring and evaluation effective, ultimately improving our health service delivery.

Thus, from the above two statements it is clear that monitoring and evaluation after the change in structure has made a good impact in efficient health service delivery. Monitoring health inequalities among sub-national levels can be aware about the substantial disparities prevalent in targeted health programs and policies [40]. Hence, it is necessary to aware the officials at subnational level about different aspects of monitoring and evaluation which ultimately helps to improve the health service delivery.

\section{Service Utilization}

Utilization of services is an indicator to assess the health service delivery. After the change in structure we interviewed the H.A. of one of the health post and he commented by saying:

We have seen a surge in utilization of services by the general public. We do not have enough private institutions delivering health services and after the recruitment of Medical Doctors, lab professionals and establishment of laboratories and Community Health Units which was all possible after the change in structure. Peoples are getting a chance to utilize quality health services.

On adding to it Head of Health and Social Development Section of Rapti Rural Municipality also said:

The steps that we have taken after the change in structures whether it be better planning, increase in infrastructure, human resources, increasing service outlets have made possible for increase in utilization of services.
Thus, the above two statements clarifies that service utilization was increased after the change in structure. This was made possible as the local government addressed the needs of people with appropriate planning, increasing human resources, developing infrastructures and being committed to it. Hence, health service delivery had a good impact after the change in structure. Change in structure of government was associated with increased service access and utilization and improved service delivery [31]. Decentralization in itself does not make sure that service delivery will be more effective to local health needs, elite groups are as likely as to fulfill their own interests as other government officials and politicians [4]. Negative outcomes of decentralization to be present in other settings were related to low performance of health professionals or inappropriate behavior of staff with patients [25]. Now the challenge presented is to further improve the quality of services and to increase the satisfaction of the public and thus increase compliance of health service delivery.

\section{Coverage of health service delivery}

To see the impact that occurred after the change in structure, we interviewed a H.A. from the health posts of Rapti Rural Municipality. He said:

Rapi Rural Municipality has been able to cover certain remote aspects by expanding its services through the community health units. Our Sisahaniya Health Post was one of the best Health Posts in Nepal and was awarded by the Government of Nepal, so we were covering the areas which came under jurisdiction of other Rural Municipalities also.

Also Head of Head and Social Development Section added that:

After the change in structure, a policy in order to expand the coverage of health services by National Health Policy 2076(2019) established three community health units which were providing basic health care services had increased the service coverage. Also, running as one of the best health posts of Nepal, we were covering areas outside of our jurisdiction also. Thus, we have good service coverage. 
The above two statements depicts that coverage of health service delivery has increased after the change in structure of government where they were able to expand the basic health services to the remote aspects in their jurisdiction. Also, they were providing good health services through one of the health posts covering more than their area which is commendable. Thus, a positive impact on coverage of health service delivery is seen. Increased resource availability leads to improvement in coverage, utilization and quality [1]. Likewise, the shift of power and resources from the federal and regional governments to local level seemed to have improved the delivery of basic services [11]. The local government should now focus on the progressive upgrade of the health posts into hospitals and community health units into health posts with expanded services so that the public would be prevented from tedious travelling for obtaining better health services. Also the partnership with private organizations must be encouraged which have significantly contributed to health service delivery.

\section{Political Situation}

Most of the administrative decisions regarding the change in structure of government necessitates political alliance and bargaining [34]. Various studies on change in political structure have mainly examined a direct link between political decentralization and service delivery outcome [38]. Considering the above knowledge we interviewed the Head of Head and Social Development Section of Rapti Rural Municipality about the political situation and he commented as:

The local representatives of Rapti Rural Municipality were inclusive with representatives from different political parties and communities and they were committed to develop their area under jurisdiction practicing democracy. The government was stable for five years so the plans and programs running were designed in such a way that they can go effectively. They were very much determined to provide an effective health service delivery and were taking this change in structure as an opportunity to contribute something to the people of the Rural Municipality and move ahead in the motto of Prosperous Nepal, Happy Nepali. They were also determined in addressing the local needs of all the people by listening to their needs and problems which were difficult at the time, before the change in structure.

The above statement gives a picture of the stable political situation of the country as well as depicts the strong commitment of different political parties to move ahead as a unit in the development of their place for providing a better service delivery. Also they were very much attached to the people of their community and were willing to address the local needs and problems to make a better community and move ahead to fulfill the motto of "Prosperous Nepal, Happy Nepali". This change in structure thus has brought a positive impact on health service delivery. Political change in structure tends to support democratization by giving opportunities for citizens and their elected representatives to influence the creation and implementation of policies [28]. Political change in structure leads to improved service delivery [37]. Policies put forth by an existing party may be modified with the next election. This discontinuity has a negative influence on building a sustainable program of services. This major issue must also be taken into account [5]. The foremost thing that must be done in regards to the political situation is to aware the politicians and local representatives about health as a sensitive matter and that it was not a subject to take advantage politically and they must act as a single team to upgrade the health service delivery and contribute to the universal health coverage.

\section{Community Participation}

Enhancing public participation will increase local accountability and improve service standards [9]. This shows that implementation of reforms necessitates community participation for it to be successful. Thus, we interviewed the Head of Health and Social Development Section of Rapti Rural Municipality about the community participation and he commented by saying:

We think that the programs or plans that are meant for the community are not successful without the interest and involvement of the community itself. We 
also know that to form plans and policies, we should make them in such a way that they are in the interest of the community. This change in structure has brought us close to the community and we ourselves were aware about the local needs and were committed to address them. We are working in close communication with the community through the elected local representative and are practicing community participation in every possible way and we have obtained very good results as well.

The above statement presents us with a scenario of the community participation at the local level. It is very satisfying to know that the people in the authority were aware about the importance of community participation in the formation and implementation of plans and policies. The practice of community participation in the Rural Municipality is commendable. Thus the change in structure has increased community participation and has provided a better health service delivery. A common aim of change in the structure of government is to make the government address public needs and encourage community participation by redesigning service delivery which is also the scenario in our context [18]. Moreover decentralization can help to increase the effectiveness of health service delivery through community participation in the decision-making process and in policy-making [31]. But in contrast a danger of decentralization was also presented, as the people who have much influence at local level may use it for their own interest. Thus, it must also be taken care of [19]. The local government, to enhance the community participation can form a civil society representing various ethnic groups, professions, members of political parties etc. so that it will be helpful in addressing the burning issues of the society which requires immediate addressing.

\section{CONCLUSIONS}

The change in structure of government was made to decentralize the previously centralized system of governance in order to increase the pace of development to remote areas of the nation. With the motto of "Singha Durbar Aba Gau Gau Ma" the government was brought close to the grassroots level to practice democratic values, enabling public in the decision making process and thus accelerating development to achieve the vision of "Prosperous Nepal and Happy Nepali". But in this due course of transition several reformations were made which created an impact on the service delivery of different sectors and health was one of them. Mixed impacts were observed. The public have expected this change in structure to be of optimum benefit but due to this transition phase their hope with the government has yet to be fulfilled. Moving ahead without a robust framework and plan of action seems to be the major factor causing smooth execution of functions. Insufficient research in this aspect also may be the cause of this haphazard situation. Despite all these challenges, comes the opportunities to solve them in various ways and fulfill the dreams of each and every Nepali who are striving to see Nepal at its optimum progress. This paper has presented a picture of the scenario in this transition period of a particular area and we cannot generalize our findings as a whole but certain burning issues which are pointed out might be helpful in the days to come. From the above results and discussions, the people who are working at the level of policy formation could take into account the current scenario and thus could formulate the plans and policies accordingly which would ease the process of decentralization. There are certain critical programs such as immunization, safe-motherhood, emergency health service delivery and others which needs to be run in an uninterrupted manner. Adequate fulfillment of human resources and their training along with different managerial skills need to be present beforehand, to ease the implementation of federalism. Positive aspects such as planning at local level, increase in service utilization, community participation and a stable political situation must also be encouraged and incorporated which are crucial factors that contribute towards a better health service delivery. Also, every country has their own geography, culture, tradition, ethnicity and economic status and thus these things must be taken into consideration for ease of implementation of decentralization. Nepal needs to find out its own way suitable for adaptation of decentralization rather than adapting from other developing or developed countries. . Thus, there is only a way forward to fulfill the expectations of all the Nepalese to progress into the path of a developed nation. 
Limitations: This study was conducted over a period of 2 months and the study site was Dang district and also the authors could include only a Rural Municipality. Purposive sampling was done to collect the data, thus, the findings, discussion and conclusion of the study cannot be generalized in the context of Nepal. A more extensive study is necessary to provide a detailed picture of the impact of change in structure of government in health service delivery.

\section{ADDITIONAL INFORMATION AND DECLARATIONS}

Acknowledgements: We are thankful to all the participants participated in this study.

Funding: Self

Competing Interests: The authors declare no competing interests.

Author Contributions: Khanal conceptualized the research, collected data, and wrote the first draft of the manuscript.
Bhandari and Poudel constructed theoretical framework, conducted literature review and analyzed the data. Dahal conducted literature review and contributed in the final check of manuscript. All authors approved the final version of manuscript.

Data Availability: Data will be available upon request to corresponding authors after valid reason.

\section{REFERENCES}

1. Agyepong IA. Reforming health service delivery at district level in Ghana: the perspective of a district medical officer. Health Policy Plan. 1999;14(1):59-69.

2. Andrews R, Boyne G, Walker R. The impact of management on administrative and survey measures of organizational performance. Public Management Review. 2011;13:227-256.

3. Coid DR, Davies H. Structural change in health care: what's the attraction? J R Soc Med. 2008;101(6):278-281.

4. Collins C. Decentralization and the need for political and critical analysis. Health Policy Plan. 1989;4(2):168-171.

5. Collins $C D$, Omar M, Hurst K. Staff transfer and management in the government health sector in Balochistan, Pakistan: problems and context. Public Adm Dev. 2000;20(3):207-220.

6. Dwicaksono A, Fox AM. Does decentralization improve health system performance and outcomes in low-and middle-income countries? A systematic review of evidence from quantitative studies. The Milbank Quarterly. 2018;96(2):323-368.

7. Ekpo A. Decentralization and service delivery: A framework paper Prepared for the African Economic Research Consortium. Published online 2008.

8. Estache A, Sinha S. Does decentralization increase public infrastructure expenditure? Decentralizing Infrastructure. Advantages and Limitations. 1995;63.

9. Foley P, Martin S. A new deal for the community? Public participation in regeneration and local service delivery. Policy \& Politics. 2000;28(4):479-492.

10. Frichi $Y$, Jawab F, Boutahari $S$, et al. Hospital logistics: an effective tool in improving the quality of care. In: ; 2018:1229-1238.

11. Garcia M, Rajkumar AS. Achieving Better Service Delivery through Decentralization in Ethiopia. Vol 132. World Bank Publications; 2008.

12. Greer $S$, Wismar $M$, Figueras J. EBOOK: Strengthening Health System Governance: Better Policies, Stronger Performance. McGraw-Hill Education (UK; 2015.

13. Kalita A, Zaidi $S$, Prasad V, Raman VR. Empowering health personnel for decentralized health planning in India: The Public Health Resource Network. Hum Resour Health. 2009;7(1):57.

14. Kapiriri L. Public participation in health planning and priority setting at the district level in Uganda. Health Policy Plan. 2003;18(2):205213.

15. Kolehmainen-Aitken RL. Decentralization and human resources: implications and impact. Human Resources for Health Development Journal. 1998;2(1):129.

16. Lakshminarayanan S. Role of government in public health:
Current scenario in India and future scope. J Family Community Med. 2011;18(1):26-30.

17. Manso JF, Annan J, Anane SS. Assessment of logistics management in Ghana Health Service. International Journal of Business and Social Research (IJBSR. 2013;3(8):75-87,.

18. Mills A. Decentralization and accountability in the health sector from an international perspective: What are the choices? Public Adm Dev. 1994;14(3):281-292.

19. Mills A, Vaughan JP, Smith DL, Tabibzadeh I, Organization WH. Health System Decentralization: Concepts, Issues and Country Experience. World Health Organization; 1990.

20. Ministry of Health and Population (MoHP. Nepal Health Infrastructure Development Standards. MoHP; 2017.

21. Ministry of Health and Population [MOHP]. Nepal Health Policy 2014. Ministry of Health (MoH); 2014. http://nnfsp.gov.np/PortalContent.a spx?Doctype $=$ Resources\&ID $=69$

22. Ministry of Health and Population [MOHP]. Nepal Health Sector Strategy 2015-2020. Ministry of Health and Population; 2015. http://climate.mohp.gov.np/news/31 -acts/154-nepal-health-sectorstrategy

23. Mishra SR, Khanal P, Dhimal M. Nepal's quest for Universal Health Coverage. J pharm pract community med. 2016;2(4):104-106. 
24. Mosadeghrad AM. Factors influencing healthcare service quality. Int J Health Policy Manag. 2014;3(2):77-89.

25. Muñoz DC, A. PM, Laura ML, David MH, Juana MSS. Decentralization of health systems in low and middle income countries: a systematic review. International Journal of Public Health. 2017;62(2):219-229.

26. Nepal Health Research Council (NHRC), Adhikary K. Evaluation study of decentralised health facilities in Nepal. Published online 2006. Accessed August 28, 2021. http://library.nhrc.gov.np:8080/nhrc /handle/123456789/192

27. Omar M. Health sector decentralisation in developing countries: Unique or universal! World Hospitals and Health Services. 2002;38(2):24-30.

28. Ozmen A. Notes to the concept of decentralization. European Scientific Journal. 2014;10(10).

29. Panda B, Thakur HP. Decentralization and health system performance - a focused review of dimensions, difficulties, and derivatives in India. BMC Health Serv Res. 2016;16(S6). doi:10.1186/s12913-016-1784-9
30. Pollitt C, Birchall J, Putman K. Decentralization in an intergovernmental context: The UK experience of managing local service delivery. In: Inter and Intra Government Arrangements for Productivity. Springer US; 1998:1529.

31. Regmi K, Naidoo J, Pilkington PA, Greer A. Decentralization and district health services in Nepal: understanding the views of service users and service providers. J Public Health (Oxf). 2010;32(3):406-417.

32. Riitta-Liisa, Kolehmainen-Aitken. The impact of decentralization on health workforce development in Papua New Guinea. Public Adm Dev. 1992;12(2):175-191.

33. Robinson M. Does decentralisation improve equity and efficiency in public service delivery provision? IDS Bull. 2007;38(1):7-17.

34. Ross AB. Health system decentralisation in Venezuela during the 1990s. Rev civilizar empresa econ. 2011;2(3):100.

35. Shah A, Thompson $T$, Zou HF. The impact of decentralisation on service delivery, corruption, fiscal management and growth.
36. Thapa $R$, Bam $K$, Tiwari $P$, Sinha TK, Dahal S. Implementing federalism in the health system of Nepal: Opportunities and challenges. Int $\mathrm{J}$ Health Policy Manag. 2019;8(4):195-198.

37. Uprety S, Lamichhane B. Health budgeting and financing in Nepal: Policy perspectives. Published online 2016.

38. Wagana DM, Iravo MA. Analysis of the relationship between devolved governance, political decentralization, and service delivery: A critical review of literature. Published online 2017.

39. World Bank. World Development Report 1993: Investing in Health, Vol.1. World Bank; 1993. doi:10.1596/0-1952-0890-0

40. World Health Organization. Strategizing National Health in the 21st Century: A Handbook. World Health Organization; 2017. 